\title{
Chlamydia trachomatis Disturbs Epithelial Tissue Homeostasis in Fallopian Tubes via Paracrine Wnt Signaling
}

\author{
Mirjana Kessler, ${ }^{*}$ Julia Zielecki, ${ }^{*}$ Oliver Thieck, ${ }^{*}$ \\ Hans-Joachim Mollenkopf, ${ }^{\dagger}$ Christina Fotopoulou, ${ }^{\ddagger}$ \\ and Thomas F. Meyer* \\ From the Department of Molecular Biology, ${ }^{*}$ and the Core \\ Facility Genomics, ${ }^{\dagger}$ Max Planck Institute for Infection Biology, \\ Berlin; and the Department of Gynecology, ${ }^{\ddagger}$ Charité University \\ Medicine, Campus Virchow, Berlin, Germany
}

The obligate intracellular pathogen Chlamydia trachomatis (Ctr) is a major cause of sexually transmitted disease and infertility worldwide. Ascending genital infections cause inflammation of fallopian tubes and subsequent scarring and occlusion. The cellular basis for such sequelae remains undetermined. We used confocal immunofluorescence microscopy to show that $\mathrm{Ctr}$ disrupts epithelial homeostasis in an ex vivo infection model of human fallopian tubes. $\mathrm{Ctr}$ triggered loss of polarity of inclusion harboring cells and of neighboring uninfected cells, as shown by subcellular redistribution of adhesion and polarity (occludin) markers. $\boldsymbol{\beta}$-catenin (a component of the adherens junction and a Wnt signaling transducer) was recruited to the bacterial inclusion, suggesting a role for Wnt signaling in $\mathrm{Ctr}$-mediated tissue damage. Comparative microarray analysis of infected epithelium in the presence of the Wnt secretion inhibitor (IWP2) demonstrated that the transcriptional response to Ctr infection was highly dependent on active Wnt secretion, moreover IWP2 reversed $C t r$-induced tissue phenotypes. Notably, we observed the up-regulation of differentiation and proliferation biomarkers olfactomedin 4 and epithelial cell adhesion molecule, and also $\mathrm{Ctr}$-induced proteolytic activation of epithelial cell adhesion molecule. Thus, acute $C t r$ infection activates the paracrine Wnt signaling pathway, leading to profound disruption of epithelial structure and function that facilitates the dissemination of damage beyond that of infected cells. (Am J Pathol 2012, 180: 186-198; DOI: 10.1016/j.ajpath.2011.09.015)
Chlamydia trachomatis (Ctr) is an obligate intracellular pathogen and a major cause of sexually transmitted disease worldwide. Recurrent Ctr infections increase the risk of infertility by $20 \%$ due to tubal occlusion and pelvic inflammatory disease. ${ }^{1}$ An estimated $5 \%$ to $10 \%$ of the sexually active population in industrialized countries is exposed to Ctr each year (National Institute of Allergy and Infectious Disease and Centers for Disease Control and Prevention). Understanding the mechanisms of Ctrinduced disease pathology, therefore, remains a matter of global public health importance.

Patent fallopian tubes provide an environment for fertilization and transport of the developing blastocyst to the uterus, and are thus essential for successful reproduction. A simple columnar epithelium builds the mucosal surface, which resides on a layer of parenchyme (lamina propria) and two layers of muscles, which enable the tube to contract. Two types of epithelial cells are found within the fallopian tubes: secretory (peg) cells and ciliated cells. Peg cells produce tubular fluid whereas ciliated cells facilitate the movement of the oocyte and spermatozoa pre-fertilization, and the zygote postfertilization. ${ }^{2,3}$

Ctr invades, and replicates within, the epithelium of the genital tract. Its unique biphasic life cycle is restricted to epithelial cells. On invasion, the metabolically inactive elementary bodies differentiate into reticulate bodies and establish a replicative niche, termed an inclusion, within the cytoplasm of the host epithelial cell. Cell culture models show that Ctr actively modulates numerous cellular processes, including vesicle trafficking, signaling, and apoptosis, to ensure successful completion of its developmental cycle. ${ }^{4-8}$ However, it remains unclear to what

Supported by the Research Training Group GRK1121 "Genetic and Immunological Determinants of Pathogen-Host Interactions" by the German Research Foundation (DFG).

Accepted for publication September 6, 2011

Supplemental material for this article can be found on http://ajp. amjpathol.org or at doi: 10.1016/j.ajpath.2011.09.015.

Address reprint request to Thomas F. Meyer, Ph.D., Max Planck Institute for Infection Biology, Department of Molecular Biology, Charitéplatz 1, Berlin, 10117 Germany. E-mail: meyer@mpiib-berlin.mpg.de. 
extent these in vitro findings are truly representative of the in vivo events. Furthermore, due to the absence of tissue regulatory mechanisms and architecture, in vitro cell culture models are inadequate for studies on the impact of Ctr on epithelial homeostasis in vivo.

The paracrine Wnt signaling pathway is not only a major player in developmental morphogenesis of epithe$\mathrm{lia}^{9}{ }^{9}$ it is also required for tissue renewal and stem cell maintenance. ${ }^{10}$ Morphogenic gradients of soluble secreted Wnt proteins coordinate the response of individual epithelial cells, depending on concentration and receptor availability. ${ }^{11}$ Wnt ligands, therefore, facilitate cell-cell communication within epithelia, and thus influence fundamental processes, such as cell migratory potential, and differentiation and proliferation rates. Mutations in Wnt pathway components are known to result in cellular transformation in several human cancers. ${ }^{12}$ The major intracellular transducer of the Wnt pathway is $\beta$-catenin, which, on activation, translocates to the nucleus and forms an active transcriptional complex with TCF/LEF family members. ${ }^{13} \beta$-catenin is also indispensable for cell adhesion, and therefore functionally integrates cell-cell communication with events in the nucleus. Although individual cell response to external Wnt-mediated stimuli depends on $\beta$-catenin signaling function, cell-cell communication and epithelial integrity are maintained by the adhesive function of $\beta$-catenin at the basolateral membranes. In contrast to the cancer cell lines routinely used in cell culture models, the epithelial layer of the fallopian tube represents a polarized, organized structure of nontransformed cells. The strength of the adherens junction, zonnula adherens, is determined by $\mathrm{Ca}^{2+}$ dependent, homophilic interactions between E-cadherin (Cdh1) molecules from neighboring cells. ${ }^{14}$

Considering the tight regulatory control of epithelial layer maintenance and renewal, it is pertinent to consider that the intracellular accommodation of Ctr may directly disrupt the homeostasis of surrounding noninfected cells. Using electron microscopy, previous ex vivo Ctr infection models of fallopian tubes have provided descriptive insights into general morphological changes, such as loss of cilia, which occur within the mucosa during infection. ${ }^{15}$ Prolonged inflammation, marked by tissue infiltrating $T$ cells and cytokine release ${ }^{16}$, is presently thought to be the main cause of the long-term tissue damage observed in Ctr-infected patients. ${ }^{17}$ However, to date, no studies have dealt with the direct response of the mucosal epithelial layer to Ctr infection by analyzing tissue integrity and functionality at the cellular and molecular levels. Here we show, using an ex vivo human fallopian tube model of Ctr infection, in concert with high-resolution confocal microscopy and tissue microarray expression profiling, that pleiotropic effects occurring within the epithelium lead to the disruption of epithelial homeostasis, and profound epithelial structural changes. Importantly, we found that paracrine Wnt signaling was activated in the infected tissue. Increased numbers of mitotically active epithelial cells were detected during infection, and notably the increase in proliferation could be suppressed with the addition of the Wnt secretion inhibitor, IWP2. Infected mucosa showed strong up-regulation and acti- vation of cell adhesion regulators and stem cells biomarkers, including epithelial cell adhesion molecule (EpCAM) and olfactomedin 4 (OLFM4).

\section{Materials and Methods}

\section{Human Samples}

Fallopian tubes were provided by the Department of Gynecology, Charité University Hospital, Campus Virchow Clinic, Berlin. Scientific usage of the samples for experimental purposes was approved by the Ethics Commission of the Charité, Berlin (EA1/002/07). Fragments were sourced from standard surgical procedures for benign gynecological diseases. Only anatomically normal fallopian tubes were used for experiments. Tubes were transported and dissected within 2 to 3 hours of removal.

\section{Chemical Treatment}

EGTA (Sigma-Aldrich, St. Louis, MO) was added to the tissue pieces at a final concentration of $10 \mathrm{mmol} / \mathrm{L}$ and incubated for 48 hours. Lithium chloride was added at a final concentration of $20 \mathrm{mmol} / \mathrm{L}$ and added to tissue samples in parallel with bacteria. IWP2 inhibitor (Calbiochem, San Diego, CA) was used at the final concentration of $5 \mu \mathrm{mol} / \mathrm{L}$. Samples of chemically treated fragments were processed in the same way as infected samples and controls.

\section{Antibodies}

Antibodies used were EpCAM (Cell Signaling 2929, Danvers, MA), $\beta$-catenin, (Sigma-Aldrich C2206), phosphorylated glycogen synthase kinase $3 \beta$ (GSK3 $\beta$ ) (Cell Signaling 9336), pHistone3 (Ser10) (Millipore CS20166, Billerica, MA), E-cadherin (BD Transduction Laboratories 610181, Dorchester, England), cytokeratin-8 (Santa Cruz Biotechnology sc-8020, Santa Cruz, CA), acetylated tubulin (Sigma 611B1), C. trachomatis (AbD Serotec OBT0978, Dusseldorf, Germany), HSP60 (Alexis ALX804-072, Lausen, Switzerland), $\beta$-actin (Sigma A5441), EpCAM intracellular domain (Epitomics 1144-1 Burlingame, CA), adenomatous polyposis coli (APC) (Chemicon MAB3786, Temecula, CA), Muc1 (Cell Signaling 4538), and C. trachomatis major outer membrane protein (University of Washington KK12).

\section{Tissue Dissection and Infection}

Fallopian tube tissue was dissected to remove extra mesenteric connective tissue. Tubes were rinsed continuously with PBS during preparation. Before infection, the tube lumen was washed with PBS using a G23 syringe. Transverse, 2- to 3-mm thick sections of the tissue (closed tube) ( $\sim 50 \mathrm{mg}$ ) were stored in MEM-Earl's medium $+10 \%$ fetal calf serum + L-glutamine. On the same day, tissue samples were infected with $C$. trachomatis serovar D $\left(5 \times 10^{6}\right.$ inclusion forming units per sample) in RPMI 1640 medium $+5 \%$ fetal calf serum and incubated 
at $35^{\circ} \mathrm{C} 5 \% \mathrm{CO}_{2}$ in a humidified incubator. For detecting infectious elementary bodies in the tissue culture, supernatants of the tissue culture containing mature, released Ctr infectious particles, elementary bodies, were removed after 3 days and titrated on Hela cell monolayers, and further incubated as previously indicated. Chlamydia inclusions were confirmed by phase contrast microscopy at 48 hours postinfection.

\section{Paraffin Embedding and Microtome Sections}

Tissues were washed with PBS, fixed in 4\% paraformaldehyde for 16 to 24 hours, washed twice with PBS, and then stored in PBS at $4^{\circ} \mathrm{C}$ until use. Tissues were dehydrated via alcohol series and perfused with paraffin in a Shandon Citadel 1000, with the following steps: 60\% (1 hour), $70 \%$ (1 hour), $80 \%$ (1 hour), 90\% (1 hour) ethanol, $2 \times 96 \%$ ethanol (2 hours), $2 \times$ isopropanol ( 2 hours), $2 \times$ acetone ( 2 hours), and $2 \times$ paraffin ( 2 hours). Tissues were embedded in paraffin blocks using a Microm Paraffin Console and cut with a Microm Paraffin Rotation Microtome into $5 \mu \mathrm{m}$ thick slices. Sections on object slides were incubated overnight at $37^{\circ} \mathrm{C}$ before use.

\section{Immunofluorescence Staining of Fixed Paraffinized Tissue}

For de-waxing and antigen retrieval of paraffin tissue sections, sample slides were placed in a glass slide holder, incubated twice with Xylene (each 5 to 10 minutes) with agitation at regular intervals, then twice with $100 \%$ ethanol (10 to 20 seconds) and once in $90 \%, 70 \%$, and $50 \%$ ethanol, each for 10 to 20 seconds, followed by two washes in water. Slides were transferred into preheated $\left(95^{\circ} \mathrm{C}\right)$ slide holders filled up with Dako target retrieval solution and incubated for 30 minutes at $95^{\circ} \mathrm{C}$, 20 minutes at room temperature, and then 5 minutes under running water. Immunofluorescence labeling of tissue sections was performed as previously described. ${ }^{18}$ Briefly, slides were removed from running water and wiped around the section. PBS $(100 \mu \mathrm{L})$ was added to the section and a DAKO Pen (DAKO, Tokyo, Japan) was used to make rings around the sections. The slide was shaken to remove excess PBS and $100 \mu \mathrm{L}$ of blocking solution (PBS $+1 \%$ bovine serum albumin + $2 \%$ fetal calf serum, filtered through $0.2-\mu \mathrm{m}$ filter) was added, and slides were placed in a moist chamber to prevent drying. Primary antibodies, diluted in blocking solution, were added for 90 minutes. After washing three times with PBS for 5 minutes, the fluorescently labeled secondary antibodies (1:200) and Draq5 (1:800), diluted in blocking solution, were incubated for 60 minutes in the dark. All steps were performed at room temperature using 20 to $40 \mu \mathrm{L}$ volumes, depending on the size of the sections. Samples were washed three times with PBS for 5 minutes and once with distilled water, and were then mounted with Mowiol (Sigma-Aldrich St Louis, MO). Dried samples were stored at $4^{\circ} \mathrm{C}$ in the dark.

\section{Microscopy}

Confocal images were acquired with a Leica TCS SP-1 microscope (Leica Microsystems GmbH, Wetzlar, Germany) using Leica Confocal Software (Leica Microsystems $\mathrm{GmBH}$ ).

\section{Microarray Analysis}

Microarray experiments were performed as dual-color hybridizations. To compensate for dye-specific effects, an independent dye-reversal color-swap was applied. ${ }^{19}$ Quality control and quantification of total RNA was assessed using an Agilent 2100 bioanalyzer (Agilent Technologies, Santa Clara, CA) and a NanoDrop 1000 spectrophotometer (Kisker Biotech, Steinfurt, Germany). RNA labeling was performed with the Low RNA Input Fluorescent Linear Amplification Kit (Agilent Technologies). In brief, mRNA was reverse transcribed and amplified using an oligo-dT-T7-promotor primer and the resulting complimentary RNA was labeled either with Cyanine 3-CTP or Cyanine 5-CTP. After precipitation, purification, and quantification, $1.25 \mu \mathrm{g}$ of each labeled complimentary RNA was fragmented and hybridized to whole human genome $4 \times 44 \mathrm{k}$ multipack microarrays (AMADID 014850), according to the supplier's protocol (Agilent Technologies). Scanning of microarrays was performed with 5- $\mu \mathrm{m}$ resolution and extended range using a G2565CA high resolution laser microarray scanner (Agilent Technologies). Raw microarray image data were analyzed with the Image Analysis/Feature Extraction software G2567AA (version A.10.5.1, Agilent Technologies) using default settings and the GE2_105_Jan09 FE protocol. The extracted MAGE-ML files were further analyzed with the Rosetta Resolver Biosoftware, Build 7.2.2 SP1.31 (Rosetta Biosoftware, Cambridge, MA). Ratio profiles comprising single hybridizations were combined in an error-weighted fashion to create ratio experiments. A 1.5fold change expression cut-off for ratio experiments was applied together with anti-correlation of ratio profiles rendering the microarray analysis highly significant $(P$ value $>0.01$ ), robust, and reproducible. Microarray data presented in this publication have been deposited in NCBls Gene Expression Omnibus (GEO at http:// www.ncbi.n/m.nih.gov/geo) and are accessible through GEO Series accession number GSE26692.

\section{Quantification of Cell Counts, Adhesion Phenotype, and Statistical Analysis}

Fallopian tubes were dissected, infected, fixed, and stained under standard experimental conditions, as previously described. Microscopic slides were analyzed by epifluorescence using a Leica DMR microscope. Mean numbers of Ser 10 phosphorylated form of histone H3 (H3P)-positive cells and proliferating cell nuclear antigen positive cells were calculated from 20 optical fields per sample (magnification 63X) and normalized to the number of counted nuclei per field. Exposure time was kept constant to ensure unbiased identification of $\mathrm{H} 3 \mathrm{P}$ - or proliferating cell nuclear antigen-positive cells. Signifi- 
cance $(P<0.05)$ was determined by paired Student's $t$-test comparing variation in counts per field of infected/ treated samples to noninfected sample. Frequency of adhesion impaired cells in the epithelial layer was calculated as a ratio of cells that exhibit phenotype to polarized cells in the optical field, counting 20 random fields per sample. Normalization was performed to the mean value of uninfected sample. Significance $(P<0.05)$ was calculated by paired Student's $t$-test.

\section{Protein Lysates and Immunoblot Analysis}

Organ pieces were transferred into $4 \mathrm{~mL}$ Greiner tubes (Greiner Bio-One, Frickenhausen, Germany) on ice with 1 $\mathrm{mL}$ ice-cold protein preparation buffer PPB (PPB: 50 $\mathrm{mmol} / \mathrm{L}$ Hepes, $330 \mathrm{mmol} / \mathrm{L}$ sucrose, $\mathrm{pH}$ 7.4, 1X "complete" protease inhibitor filtered through $0.2 \mu \mathrm{m}$ filter). Tissue was homogenized by $3 \times 15$ seconds pulses with an Ultra-turrax (IKA, Staufen, Germany) at maximum speed on ice; lysates were centrifuged for 10 minutes at $20,000 \times g$ at $4^{\circ} \mathrm{C}$. Protein concentration in the lysates was determined by BCA protein assay reagent (Thermo Fisher Scientific, Rockford, IL).

Samples were boiled after addition of $1 \times$ SDS loading dye to the supernatants and analyzed on a reducing SDS-polyacrylamide gel. After separation, samples were transferred to a polyvinylidene difluoride membrane and incubated with specific antibodies. After binding of horseradish peroxidase-conjugated secondary antibodies, ECL reagent (GE Healthcare, Amersham, England) was used for detection on X-ray films.

\section{RNA Isolation and Real-Time PCR}

Organ pieces were transferred into $2 \mathrm{~mL}$ tubes on ice with 0.4-mL ice-cold RLT buffer (RNeasy Mini Kit, Qiagen, Hilden, Germany) and homogenized with three 20-second pulses of an Ultra-turrax (IKA) at maximum speed, on ice. Lysates were centrifuged for 10 minutes at 20,000 $\times g$ at $4^{\circ} \mathrm{C}$ and RNA isolated from resulting supernatants, according to the manufacturer's protocol (Qiagen). Real-time PCR was performed using Quantitect SYBR Green RT-PCR kit (Qiagen), on ABI Prism $7900 \mathrm{H}$ sequence detection system (Applied Biosystems, Darmstadt Germany). Reactions performed in $25 \mu \mathrm{L}$ contained 100 ng RNA, 12.5- $\mu \mathrm{L}$ SYBR Green mix, 0.25- $\mu \mathrm{L}$ RT mix, and $0.4-\mu \mathrm{mol} / \mathrm{L}$ per primer.

Program: 30 minutes $50^{\circ} \mathrm{C}$; 15 minutes $95^{\circ} \mathrm{C}$; followed by, $45 \times$ cycles of 20 seconds $94^{\circ} \mathrm{C} / 40$ seconds $60^{\circ} \mathrm{C} / 40$ seconds $72^{\circ} \mathrm{C}$. Primers: glyceraldehyde-3-phosphate dehydrogenase forward 5'-GGTATCGTGGAAGGACTCATGAC-3', reverse 5'-ATGCCAGTGAGCTTCCCGTTCAG-3'; EpCAM forward 5'-AATGTGTGTGCGTGGGA-3', reverse 5'-TTCAAGATTGGTAAAGCCAGT-3'; OLFM4 forward 5'-GCTCCAGCCGCAGCTTAG-3', reverse 5'-GGAGCCGGTGAAATTGGAA-3'; DEF4 forward 5'-TCCAGTCTTTTGCCCTAGAAGGT-3', reverse 5'-TGGCTTTTTGCAGCATTTTG-3'; SP100 forward 5'-TCTGGCCTCCAACTAAGTCTTGA-3', reverse 5'-ACCCGAAGGTGGCCAAGT-3'; TCF2 forward 5'-GAGACAAGGAACCACCGAAGAG-3', reverse 5'-TCGCATCAGTTTGTTCGATGA-3'; octamer binding tra- nscription factor 4 forward 5'-GATGTGGTCCGAGTGTGGTTCT-3', reverse 5'-TTGTGCATAGTCGCTGCTTGA-3'; LCN2 forward 5'-GAACTTCATCCGCTTCTCCAAA-3', reverse 5'-GTCGATTGGGACAGGGAAGA-3'.

For each oligonucleotide pair, the sample reaction was performed in triplicate. Relative expression level of the target gene was normalized to the expression of glyceraldehyde-3-phosphate dehydrogenase in each individual sample amplification plots were analyzed with the $A B I$ Prism SDS Software package (version 2.2.2; Applied Biosystems). Relative quantification of gene expression was performed by the comparative $\mathrm{Ct}$ (threshold cycle) ${ }^{20} \mathrm{cal}-$ culating $\Delta \Delta \mathrm{Ct}$. The parameter $\mathrm{Ct}$ is defined as the cycle number at which fluorescence passes the fixed threshold. Statistical analysis was performed by calculating $P$ value (paired Student's $t$-test) for mean $\Delta C$ t values between different biological replicates. Significance was set at $P<0.05$.

\section{siRNA Transfection}

Small-interfering RNAs (siRNAs) were purchased from Qiagen and were validated at the Max Planck Institute for Infection Biology (Berlin, Germany) for their ability to knockdown mRNA expression of target genes by more than 70\% in comparison to cells transfected with a control siRNA against luciferase. Cells were seeded in 12-well plates, grown to $50 \%$ to $70 \%$ confluency, and transfected using HiPerFect (Qiagen). Six $\mu$ L of siRNA (si $\beta$-cat, siLuci) diluted to $2 \mu \mathrm{mol} / \mathrm{L}$ in serum-free medium was mixed with $100 \mu \mathrm{L}$ serum free medium and $6 \mu \mathrm{L}$ HiPerFect and incubated for 10 minutes at room temperature. The mixture was added dropwise to cells in $1 \mathrm{~mL}$ culture media. Cells were trypsinized after 24 hours and seeded into new plates. Infection was performed 72 hours after siRNA transfection.

\section{Infectivity Assay}

Infectious progeny were harvested from infected cells 48 hours after the primary infection by cell lysis with glass beads and titration of the supernatant containing released elementary bodies onto a HeLa cell monolayer, seeded the previous day. Cells were incubated for 24 hours at $35^{\circ} \mathrm{C}$, $5 \% \mathrm{CO}_{2}$, fixed in methanol, stained for chlamydial major outer membrane protein and inclusions were counted as an average of 10 optical fields per sample. Inclusion numbers after knockdown of target genes were calculated as inclusion forming units and expressed as a percentage of the luciferase siRNA control.

\section{Results}

\section{Ex Vivo Fallopian Tube Infection Model}

To delineate the influence of Ctr on the integrity of epithelial tissues, we established an ex vivo infection model using human fallopian tubes and analyzed samples by high-resolution, immunofluorescence confocal microscopy. We used Ctr serovar D, which is one of the genital serovars (D-K) known to be causative agents of sexually 

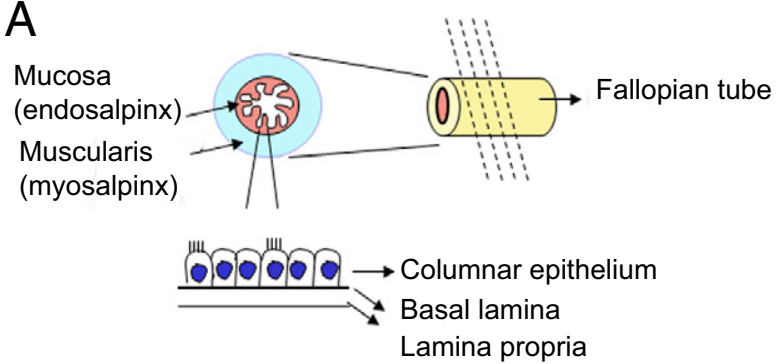

$\mathrm{B}$

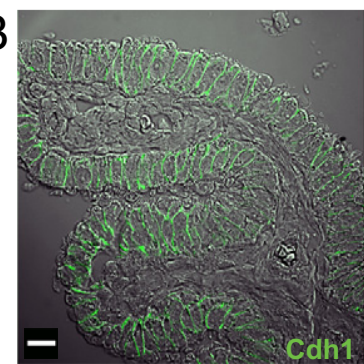

$\mathrm{D}$

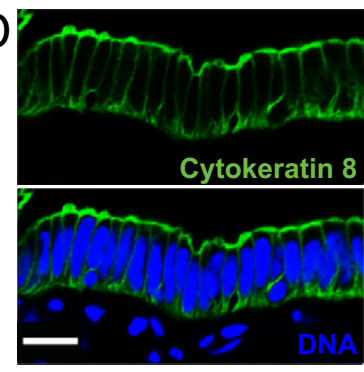

$\mathrm{F}$

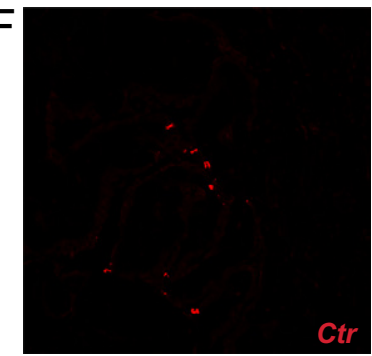

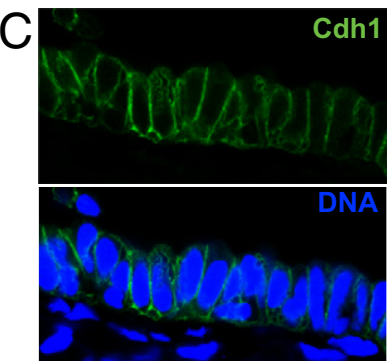
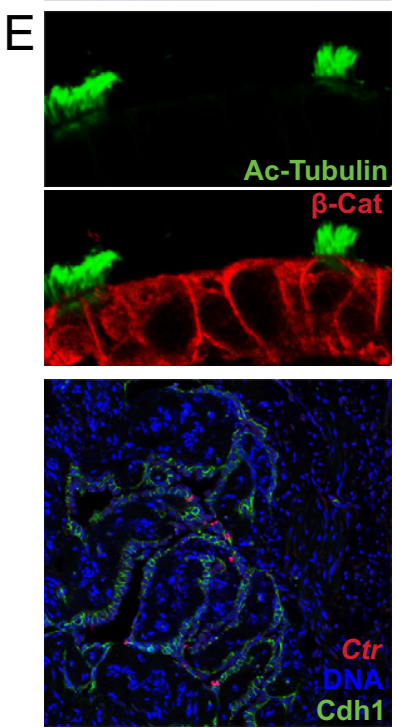

Figure 1. Ex vivo model of Ctr infection in fallopian tubes. A: Schematic representation of Fallopian tube tissue architecture. The mucosal epithelium (endosalpinx) envelops the inner surface of the fallopian tube and resides on connective tissue, the lamina propria. Two layers of visceral muscles in the muscalaris (myosalpinx) provide mechanical support and contractility of the tube (arrows). Within the mucosal epithelium two types of epithelial cells can be discriminated: secretory cells and ciliated cells. B: Tissue sample fixed after three days in culture and processed for indirect immunofluorescence of anti E-cadherin (Cdh1) (green); Overlay with transmission light microscopy picture. Cdh1 marks the basolateral cell outlines of the epithelium exclusively. C: Higher magnification of a tissue sample stained for Cdh1 (green) and DNA (Draq 5) (blue); basolateral cell outlines of epithelial cells are readily visible. D: Tissue sample stained for cytokeratin- 8 (green) and DNA (Draq 5) (blue); cytokeratin-8 accumulates at the apical plasma membrane. E: Tissue sample stained for the cilial marker acetylated $\alpha$-tubulin (AcTubulin) (green) and the basolateral marker $\beta$-catenin ( $\beta$-Cat) (red) F: Tissue sample incubated with Ctr for 24 hours stained for Cdh1 (green), Ctr (red) and DNA (Draq 5) (blue); Ctr is detected only in epithelial cells. Scale bar = $16 \mu \mathrm{m}$.

transmitted disease. The primary host cell tissue, the mucosal epithelial layer, was rendered accessible for Ctr infection by limited dissection of tubal fragments (Figure $1 \mathrm{~A})$, which were obtained as remnants from unrelated gynecological procedures. Epithelial viability and function, as well as preservation of structural tissue integrity, were determined for five days in culture. The epithelial layer was visualized with the cell type-specific markers Cdh1 and cytokeratin-8. Cdh1 localized to the basolateral plasma membrane of epithelial cells (Figure 1, B and C) and all cells within the epithelial layer expressed cytokeratin-8 (Figure 1D), indicating preservation of intact tissue architecture. Staining for acetylated tubulin discriminated ciliated from secretory cells (Figure 1E). Ctr elementary bodies, retrieved from tissue culture supernatants of infected fallopian tubes readily infected HeLa cells (data not shown), confirming the ability of the pathogen to successfully complete its developmental cycle in ex vivo tissue culture. Furthermore, single-cell analyses revealed that Ctr was located exclusively within the single layered cuboidal mucosal epithelium of fallopian tubes and did not infect the underlying lamina propria (Figure 1F); features that are consistent with previous observations. ${ }^{15}$

\section{Ctr Infection of Fallopian Tubes Disrupts Epithelial Cell Adhesion and Polarity}

Loss of epithelial adhesion is the first step in the process of epithelial mesenchymal transition, a cellular mechanism critical for tissue development and a hallmark of tissue injury, fibrosis, and carcinogenesis. ${ }^{21}$ To elucidate a molecular basis for the development of pathology during Ctr infection, we aimed to identify early events in the infected fallopian tube epithelia. Confocal imaging of specific epithelial markers revealed substantial phenotypic changes in the epithelium of all analyzed tissue specimens ( $n=\sim 60$ ) after two days of Ctr infection. Functional integrity of the epithelium can be shown by immunostaining against Cdh1, the main component of zonula adherens (Figure 2A). In contrast to the restricted basolateral distribution of Cdh1 in noninfected tissue (Figure 2B, left), Cdh1 was frequently distributed throughout the whole plasma membrane in Ctr infected samples (Figure 2B, right, arrows); a phenotype reminiscent of the breakdown of organized cell contacts and the loss of the apical plasma membrane domain. We also observed a multi-layering of the epithelium in infected tissue, a hallmark of apical-basal polarity loss within mucosal surfaces. ${ }^{22}$ Intriguingly, a similar cell morphology and redistribution of Cdh1 were observed in neighboring uninfected cells (Figure 2B right). To quantify the effect of Ctr infection on epithelial cell adhesion disruption we determined the percentage of cells with clearly defined polarity, per field of view, using apico-basal orientation, visible lateral Cdh1 domains, and absence of apical Cdh1 signal as criteria. Although occasional cells that are not polarized are found in noninfected mucosa, likely due to cell division or apoptosis, the frequency of the adhesion disrupted phenotype is significantly increased in Ctr infected samples (fivefold to sevenfold increase) (Figure 2C). This phenotype could also be induced by treatment of noninfected samples with the $\mathrm{Ca}^{2+}$-chelating agent EGTA (10 mmol/L; Figure 2D), which inhibits Coh1-dependent cell adhesion in cultured epithelial monolayers. ${ }^{23}$ To confirm the loss of cell polarity, we determined the distribution of occludin, an integral membrane protein 
A

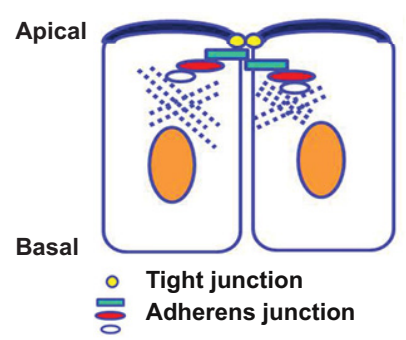

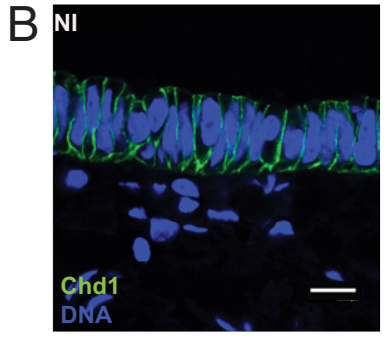

$\mathrm{D}$
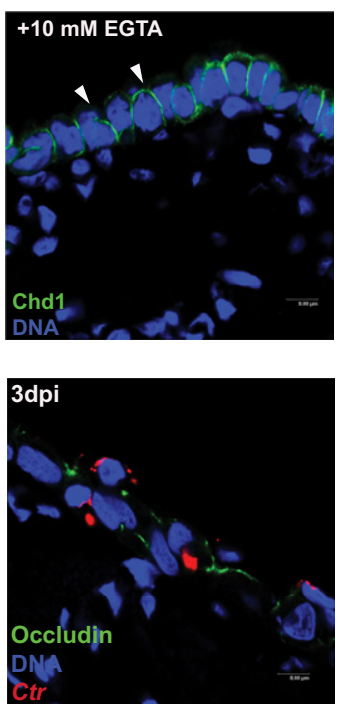

DN.
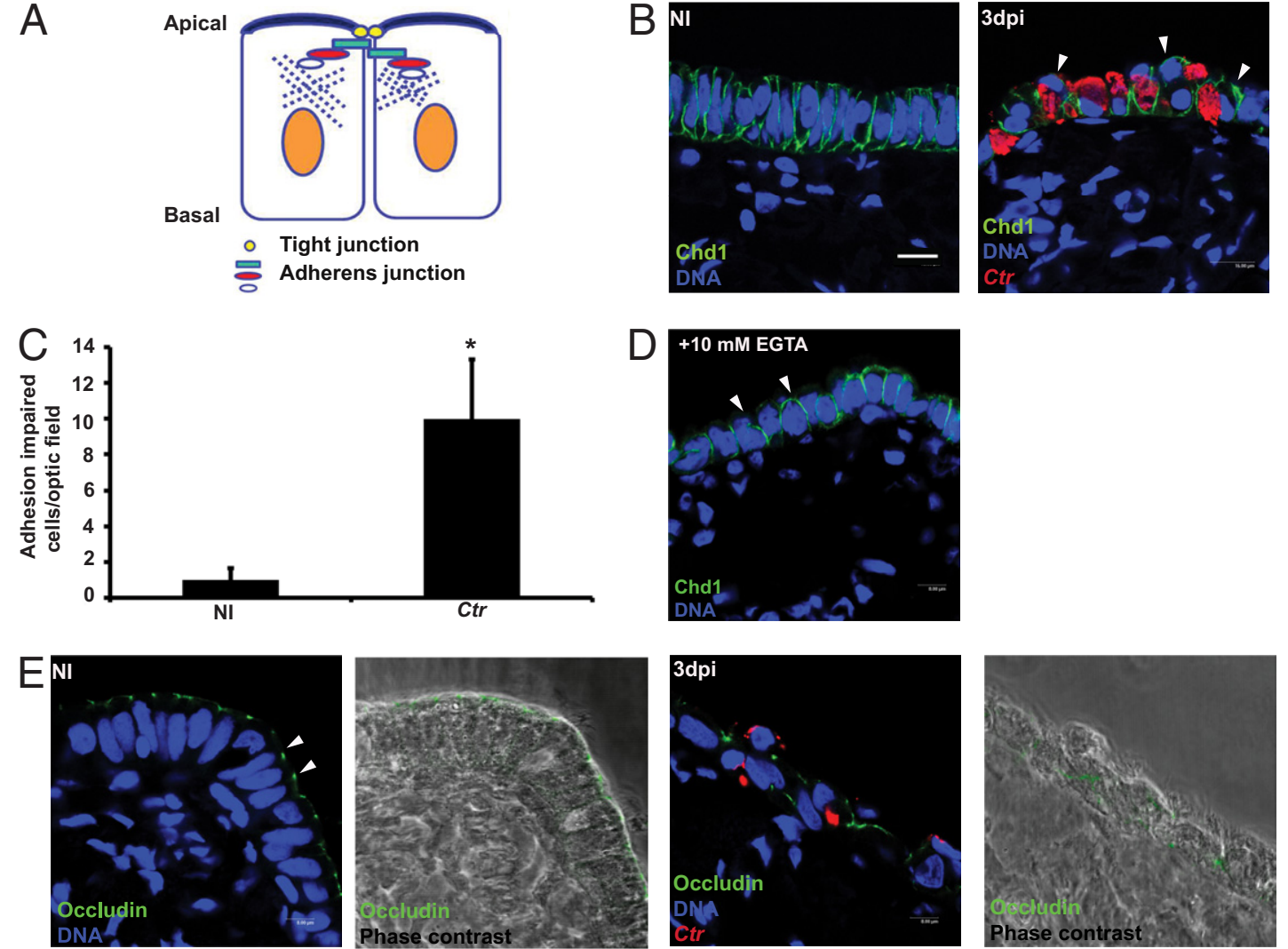

Figure 2. Ctr infection triggers loss of cell adhesion and polarity in fallopian tube epithelium. A: Schematic representation of ultrastructural organization within the epithelium. Polarity is maintained along the apico-basal axis. Protein complexes, components of tight junctions, and zonula adherens junctions form a contact zone with neighboring cells and separate apical and basolateral domains of the plasma membrane. In the extracellular space, adhesion is facilitated through homotypic interactions of E-cadherin (Cdh1) (blue) in the presence of $\mathrm{Ca}^{2+}$ ions. $\beta$-catenin (red) provides the link between Cdh1 and the actin cytoskeleton. B: Analysis of Cdh1 staining in NI and Ctr infected (3 dpi) fallopian tubes. (Cdh1; green: DNA; blue: Ctr, red) (left) A basolateral distribution of Cdh1 is observed in NI tissue. (right) Chd1 is detected along the plasma membrane and cells exhibit rounded cell morphology in infected tissues (arrowheads). C: $C$ tr infection increases number of detected cells with impaired adhesion, as a fraction of total epithelial cell count in the optical field, normalized to NI sample. Data are representative of two different infections of independent tissue samples. Significant difference of * $P<0.05$; paired Student's $t$-test. Errors are \pm SD and are calculated based on the internal variation adhesion impaired cells/polarized cells in individual sample. D: Loss of adhesion phenotype is induced by adding $10 \mathrm{mmol} / \mathrm{L}$ EGTA to the tissue culture in the absence of infection. The $\mathrm{Ca}^{2+}$-chelating substance causes disruption of Cdh1 interactions and loss of cell adhesion (arrowheads). E: Localization of the tight junction protein occludin (green). (left) In NI samples, occludin is exclusively found at tight junctions (arrowheads); (right) during Ctr (red) infection, occludin is lost from subapical regions, indicative of a loss of cell polarity. Phase contrast images of tissue samples reveal global morphological changes in mucosa induced by $\mathrm{Ctr}$ infection. Scale bar $=16 \mu \mathrm{m}$. NI, noninfected; dpi, days postinfection.

localizing to the tight junctions. ${ }^{24}$ Immunostaining revealed a distinct loss of occludin from subapical regions in Ctr-infected mucosa, as compared to noninfected epithelium (Figure 2E). Thus, we observed that during Ctr infection of the fallopian tubes, both cell polarity and Cdh1-mediated cell adhesion, were disrupted. Most interestingly, these changes were not restricted to infected cells, but extended toward the neighboring tissue, suggesting that Ctr infected cells engage in the stimulation of a paracrine signaling pathway.

\section{$\beta$-Catenin Is Recruited to the Ctr Inclusion}

To address the molecular mechanisms underlying the loss of cell adhesion on Ctr infection, we analyzed the distribution of $\beta$-catenin, a major cytoplasmic interaction partner of Cdh1 that mediates cell adhesion and is also critical for Wnt signaling transduction. ${ }^{25}$ In noninfected cells, $\beta$-catenin localized to the same basolateral membrane domain compartment as Cdh1 (Figure 3); however, in infected cells $\beta$-catenin strongly co-localized with internalized Ctr at the lateral plasma membranes of epithelial cells in the proximity of zonula adherens after 8 hours of infection (Figure 3A, upper row). At later infection times (24 to 48 hours) we observed strong co-localization of $\beta$-catenin with the inclusion surface (Figure 3A, middle and bottom row). Interestingly, in cultured HeLa cells the knockdown of $\beta$-catenin using siRNA ( $\sim 75 \%$ at the protein level determined by Western blot, data not shown) resulted in a twofold reduction of Ctr infectivity (Figure 3B), indicating that $\beta$-catenin recruitment to the Ctr inclusion is beneficial for the pathogen. In turn, the observed disturbances of host cell polarity and cell adhesion in the infected tissue could be explained by changes to membrane adhesion complexes of which $\beta$-catenin is an important component.

\section{Wnt Signaling Is Deregulated on Ctr Infection}

The cytoplasmic pool of $\beta$-catenin is tightly regulated and is readily degraded by the Wnt pathway inhibitory complex. ${ }^{26}$ Thus, given our observation that $\beta$-catenin is recruited to the Ctr inclusion, we reasoned that infection 

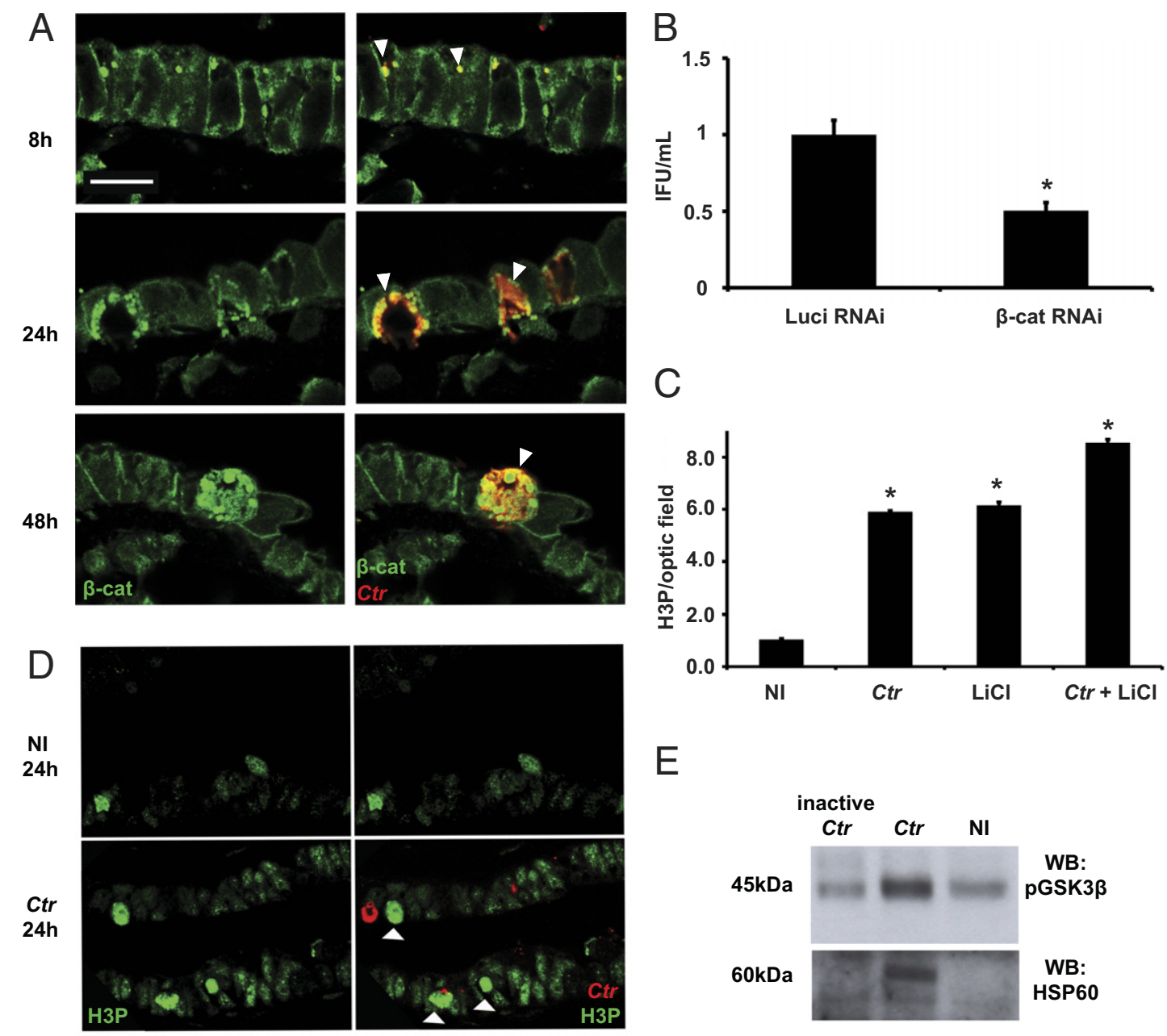

$E$

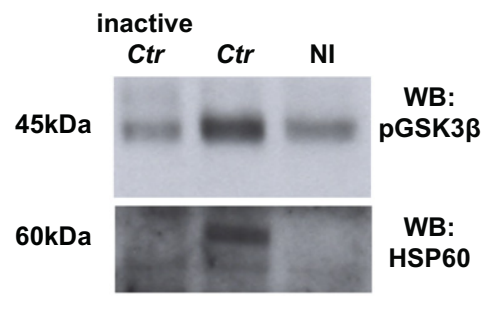

Figure 3. $\beta$-catenin is recruited to the $C t r$ inclusion and is required for bacterial replication. A: $\beta$-catenin (green) and $C t r$ (red) localization in epithelial cells over an infection time course of 8 to 48 hours. Scale bar $=16 \mu \mathrm{m}$. (A) $\beta$-catenin is recruited to the chlamydial inclusion after 8 hours of infection (arrowheads) (ie, when the early inclusion resides in the proximity of lateral membrane). (A, middle and lower panels) At later infection time points of 24 and 48 hours, patches of $\beta$-catenin are associated with inclusions membranes (arrowheads). Scale bar $=16 \mu \mathrm{m}$. B: Chlamydial infectivity on small-interfering RNA (siRNA)-mediated knockdown of $\beta$-catenin is reduced twofold in comparison to cells treated with a nonspecific siRNA (Luci RNAi). Numbers of infectious progeny calculated as inclusion forming units (IFU)/mL and expressed as a fraction of control (Luci RNAi). Data are representative of three independent experiments. Error is mean \pm SD calculated on the variation of inclusion count per optical field. Significant difference of * $P<0.05$; paired Student's $t$-test. C: $C t r$ infection leads to a fivefold increase in the number of histone $\mathrm{H} 3$ (H3P)-positive cells, similar to lithium chloride treatment. Treatment of infected tissue with 20 mmol/L lithium chloride shows a mild additive, mitosis-inducing effect. Data are representative of three independent experiments; $n=20$ fields of view per sample, normalized to the number of nuclei per field. Significant differences of ${ }^{*} P<0.05$; paired Student's $t$-test. D: To identify actively dividing cells in infected fallopian tubes, samples were stained for the mitosis marker Ser10 phosphorylated form of H3P (green). Confocal imaging shows increased frequency of H3P-positive cells in infected epithelia in comparison to noninfected (NI) (control) tissues (arrowheads) ( Ctr, red). Scale bar $=16 \mu \mathrm{m}$. E: Immunoblot analysis of protein lysates for presence of the inactive form of glycogen synthase kinase $3 \beta$ (GSK3 $\beta$ ), ie, phosphorylated glycogen synthase kinase $3 \beta$ (pGSK3 3 ), and the Ctr heat shock protein 60 (HSP60) in $C t r$ infected, noninfected, and heat-treated (inactive) samples. Infected tissue lysate is positive for HSP60. pGSK3 $\beta$ levels are elevated in Ctr infected lysates. Images in $\mathbf{D}$ and blots in $\mathbf{E}$ are representative of experiments with five independent patient samples.

could alter its steady state equilibrium in the cytoplasm, not only affecting adhesion of Ctr infected cells, but also deregulating Wnt signaling in the tissue. Indeed, we observed prominent adhesion changes in noninfected cells, which were accompanied by increased cytoplasmic levels of $\beta$-catenin (see Supplemental Figure S1 at http:// ajp.amjpathol.org). These changes were indicative of activation, rather than inhibition of Wnt signaling, and were suggestive of Wnt signaling disruption in the entire epithelium, including both infected and noninfected cells.

A hallmark of Wnt deregulation is an alteration of cell proliferation rates within diseased tissue. ${ }^{27}$ To quantify mitotic rate in the Ctr-infected fallopian tube samples, we immunostained tissue sections for mitotic marker, H3P. ${ }^{28}$
Ctr infection led to an approximate sixfold increase in the number of H3P-positive epithelial cells per optic field in comparison with noninfected control tissue (Figure 3, C and D), suggesting increased proliferation and altered epithelial cell homeostasis. The Ctr-dependent effect was comparable to the mitotic induction observed after treatment with lithium chloride for 24 hours (Figure 3C). Lithium chloride is a chemical inhibitor of GSK $3 \beta,{ }^{29}$ which is a negative regulator of $\beta$-catenin stability. ${ }^{26}$ Thus, Ctrinduced remodeling of the epithelial monolayer is reminiscent of other effectors known to cause aberrant activation of the Wnt signaling pathway.

To investigate the mechanism underlying the observed Ctr-dependent proliferation of epithelial cells, we deter- 
A
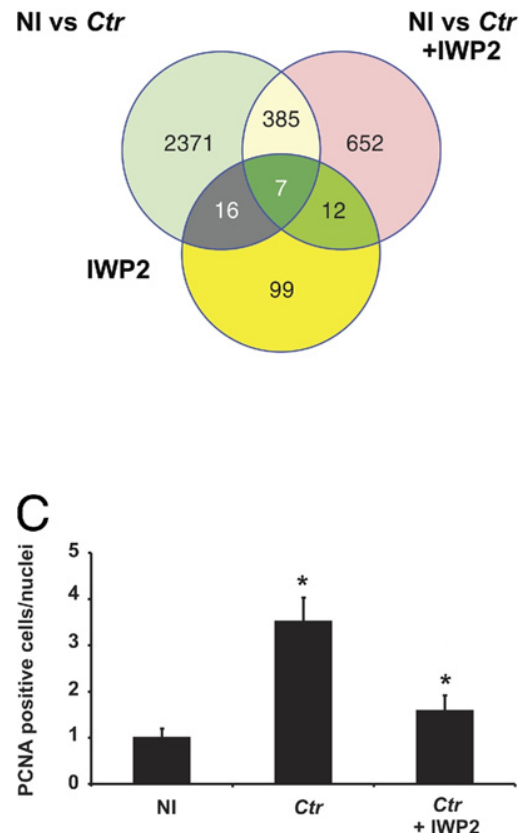

B

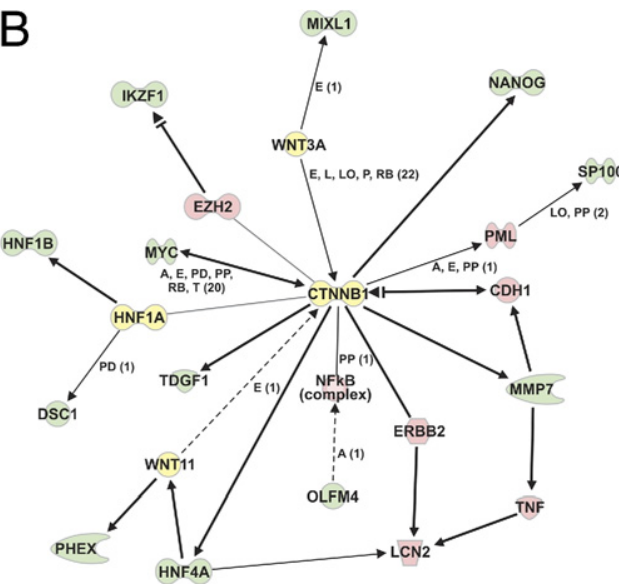

D

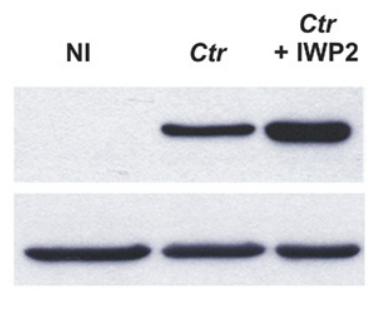

Figure 4. Blocking of paracrine Wnt release inhibits tissue response to infection, while Ctr replication is enhanced. A: Venn diagram of differentially regulated genes in the presence of Wnt inhibitor IWP2 during Ctr infection (48 hours postinfection). Ctr infection drives strong transcriptional responses in the fallopian tube. Response is strongly suppressed if Wnt signaling transmission is interrupted by IWP2. B: Cellular pathway generated by Ingenuity Pathway Analysis (Ingenuity Systems, Redwood City, CA) representing selected regulated target genes (green) and their relationship to $\beta$-catenin (CTNNB1, yellow) in the center. Candidates were found to be up-regulated in normal $\mathrm{Ctr}$ infection, but not regulated in Ctr-infected samples in the presence of IWP2. C: Quantitative analysis of proliferating cell nuclear antigen (PCNA)-positive cells per field view in Ctr-infected fallopian tube samples. Ctr infected samples show increase in cell division, an effect that is inhibited if Wnt signaling is blocked by IWP2. Number of fields counted per sample $=10$. Experiment is representative of three independent experiments. Errors are \pm SD and are calculated based on the internal variation of PCNA positive cells/ nuclei in individual samples. Significant differences ${ }^{*} P<0.05$; paired Student $t$-test. D: Western blot of protein samples from epithelial cell lysates determining $\mathrm{Ctr}$ bacterial load in fallopian tube \pm IWP2 with anti-HSP60 as a marker $\mathrm{Ctr}$ replication is increased in tubes treated with IWP2. Blot is representative of three independent experiments with three different samples/ infections. NI, noninfected. mined the activity of GSK3 $\beta$ in infected tissues. The phosphorylated form of GSK3 $\beta$ serves as a marker of its inactivation. ${ }^{30}$ Immunoblotting of whole tissue lysates showed increased levels of phospho-GSK3 $\beta$ in infected samples, as compared to control tissues (noninfected and heat-inactivated Ctr) (Figure 3E). Interestingly, we observed redistribution of APC protein in infected tissue, particularly in neighboring, uninfected cells (see Supplemental Figure S2 at $h$ ttp://ajp.amjpathol.org). APC is the key component of the $\beta$-catenin degradation complex and one of the most wellcharacterized tumor suppressor genes, with significance for the etiology of colorectal cancer. ${ }^{31}$ In noninfected mucosa, APC localized to the subapical region of epithelial cells, and exhibited a distinct granular pattern. By contrast, staining of infected samples revealed diffuse distribution of APC throughout the cytoplasm. Taken together, the increased proliferation of epithelial cells, the suppression of GSK3 $\beta$ activity, and the re-localization of APC in infected tissues were consistent with enhanced Wnt signaling during Ctr infection.

\section{Paracrine Wnt Signaling Stimulates Transcriptional Response of Fallopian Tube Epithelium to Ctr Infection}

To test the hypothesis that Ctr infection activates the Wnt pathway in the surrounding epithelium via a paracrine route, we aimed to disrupt Wnt signaling in our tissue to compare the outcome of infection on epithelial homeostasis. Recently, a class of potent small molecule compounds has been identified that specifically inhibit secretion of Wnt and antagonize the Wnt pathway. ${ }^{32}$ IWP2 specifically inhibits the maturation of Wnt proteins by blocking porcupine acetyltransferase. Porcupine acetyltransferase localizes to endoplasmic reticulum membranes and modifies Wnt proteins before secretion. IWP2 does not, however, affect general protein secretion or the activity of other paracrine signaling pathways, such as Notch. ${ }^{32}$ We isolated total RNA from noninfected and Ctr infected tubal sections and compared gene expression profiles in the presence and absence of IWP2 (5 $\mu \mathrm{mol} / \mathrm{L})$ using microarray analysis. RNA was retrieved from two independent experiments with samples from two female donors to ensure identification of Ctr regulated genes independent of host genetic polymorphisms. We identified 2279 genes to be differentially regulated in response to Ctr infection (Figure 4A). The up-regulated genes not only comprised pro-inflammatory determinants, such as interleukin, cytokine, and immune response mediator genes; but also numerous genes involved in control of cell growth, proliferation, adhesion, and differentiation.

Intriguingly, blocking the Wnt pathway by adding IWP2 during Ctr infection reduced the number of significantly regulated genes in the infected fallopian tubes to 1056. Importantly, inhibitor alone exhibited only minor influence on gene expression in the fallopian tube tissue samples (Figure 4A) with 35 genes found to be differentially regulated also in Ctr infection. Therefore, the strong inhibition of Ctr induced gene activation by IWP2 cannot be attributed to a pathogen-independent inhibitor action. The differentially regulated gene sets were uploaded to the software platform Ingenuity Pathway Analysis (Ingenuity Systems, Redwood City, CA) for biomining and functional analysis. Data analysis and network assembly for selected hits showed that genes regulated in infection and responsive to IWP2 were clearly linked with $\beta$-catenin 
mediated Wnt signaling, either as direct targets or downstream of directly regulated proteins (Figure 4B). All genes shown in green were found to be up-regulated during Ctr infection and regulation was inhibited in the IWP2-treated samples. Next, we tested if IWP2 responsive gene expression changes were reflected at the tissue level during infection. Cell division rates in the tissue were analyzed by staining the samples with antibody against proliferating cell nuclear antigen, another marker of actively dividing cells. Indeed, blocking Wnt activity and secretion using IWP2 led to a marked reduction ( $\sim$ twofold) of the increased mitosis observed during Ctr infection (Figure 4C). Interestingly, IWP2-mediated inhibition of Wnt secretion had a positive effect on the replication of Ctr, observed by comparison of the levels of the Ctr structural protein, HSP60, in Ctr-infected samples, compared with noninfected samples (Figure 4D). Therefore, the marked suppression of transcriptional response and reduction of mitotic rate by IWP2 cannot be attributed to an IWP2-mediated inhibition of Ctr infection. On the contrary, activation of Wnt secretion in response to Ctr infection appeared to be the causative signaling event that mediated a pleiotropic response over the whole mucosa constraining pathogen replication within the infected host tissue.

\section{Wnt-Dependent Up-Regulation of the Stem Cell Marker OLFM4 in Infected Fallopian Tubes}

Among the genes identified by microarray as being differentially regulated during $\mathrm{Ctr}$ infection of fallopian mucosa, one of the top hits exhibiting $\sim 132$-fold induction was OLFM4. OLFM4 is a glycoprotein that localizes to different intracellular compartments and also to the extracellular space. ${ }^{33}$ It binds cadherins and lectins, and thereby modulates cellular adhesion. Furthermore, OLFM4 is found to be highly enriched in adult stem cells, in particular in $\mathrm{Lgr5}^{+}$populations of intestinal and gastric mucosa. ${ }^{34}$ We validated the induction of OLFM4 in the fallopian tube Ctr infection model by real-time PCR with samples from three different women and three independent Ctr infections. Overall, the level of OLFM4 mRNA was increased in Ctr infected samples 100-fold. Interestingly, the up-regulation mechanism also appeared to be dependent on Wnt pathway activity because IWP2 suppressed induction $\sim 10$-fold (Figure $5 \mathrm{~A}$ ). Induction of OLFM4 in fallopian tube epithelium was confirmed by confocal imaging of infected samples using anti-OLFM4 (Figure 5B). In noninfected epithelial cells, signal intensity for anti-OLFM4 was very low, consistent with low mRNA levels identified by real-time PCR. By comparison, Ctr infection caused a visible increase in signal intensity for OLFM4 in all epithelial cells (ie, infected and noninfected). Notably, OLFM4 immunostaining was uniform throughout the epithelium, while we observed that immunostaining of the submucosa was limited to isolated cells. In addition to OLFM4 up-regulation, we also validated the Wnt dependent up-regulation of other selected hits from the microarray analysis using real-time PCR: DEF4, LCN2,
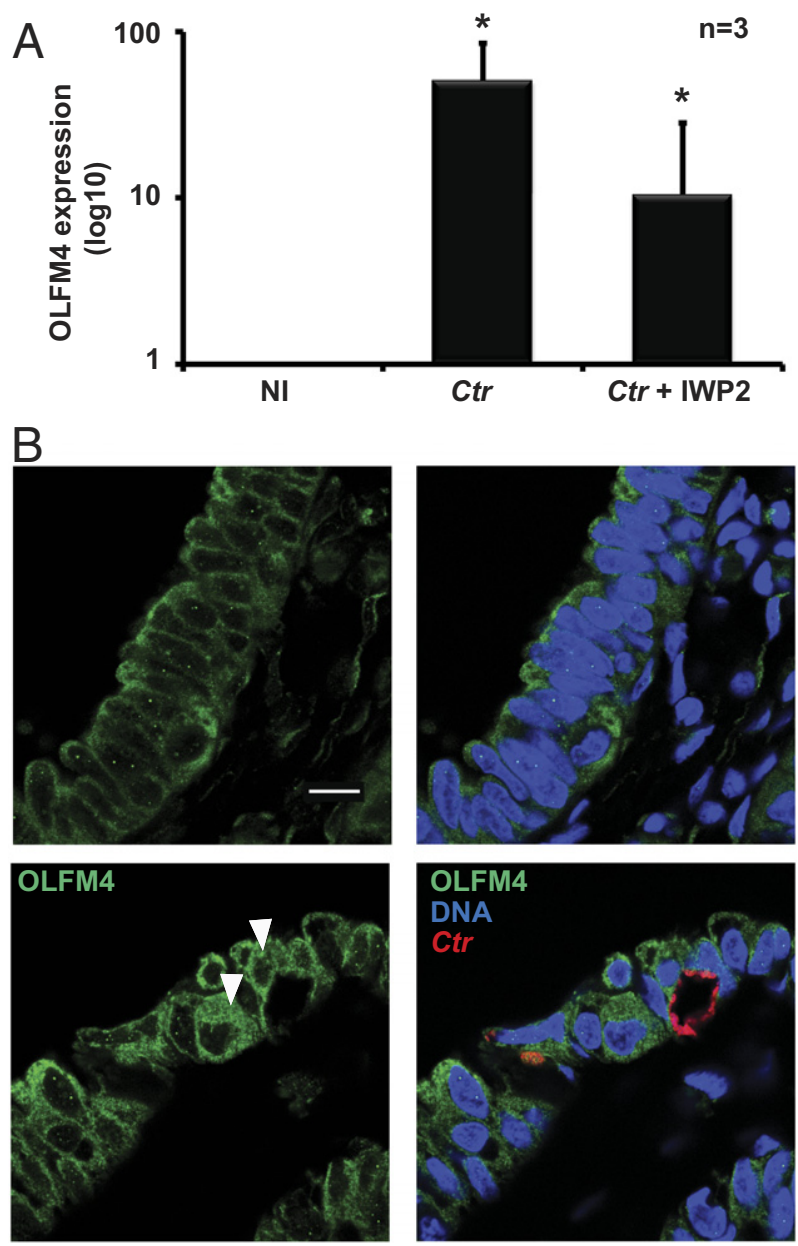

Figure 5. Stem cell marker olfactomedin 4 (OLFM4) is significantly up regulated in the infected fallopian tube in a paracrine fashion. A: Real-time validation of OLFM4 expression. Ctr induces strong up-regulation in OLFM transcription with average change of $\sim 100$-fold. Addition of IWP2 reduces this effect to $\sim 10$-fold. Error bars \pm SD from three independent experiments, with calculations based on variation in $\Delta \mathrm{Ct}$ among independent biological samples. Significant difference of ${ }^{*} P<0.05$ versus noninfected (NI) sample (paired Student's $t$-test. B: Confocal images of Ctr-infected cells stained against anti-OLFM4 (green); Ctr (red), OLFM4 is detected in low amounts in epithelial cells in NI fallopian mucosa. Ctr-infected tissue shows higher expression of OLFM 4 signal in all epithelial cells. This is especially prominent in the granular staining pattern in the enlarged cytoplasm of phenotypically altered epithelial cells from infected samples (arrowheads).

SP100, OCT4, and TCF2 (see Supplemental Figure S3 at http://ajp.amjpathol.org).

\section{Ctr Infection Induces Up-Regulation and Activation of EpCAM}

Because changes in cell adhesion, polarity, and proliferation are the main phenotypic characteristics of Ctr-infected fallopian tube epithelium, we searched for other known modulators of cell adhesion and proliferation that could contribute to the observed cellular changes. One of the major markers of ovarian neoplastic tissue is overexpressed EpCAM. ${ }^{35}$ EpCAM is an adhesion protein that negatively modulates the strength of Cdh1-mediated cell adhesion. ${ }^{36}$ Due to cellular changes in Ctr-infected tissue being consistent with reduced Cdh1-mediated cell adhe- 
A

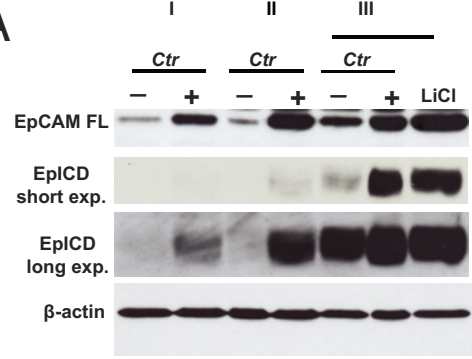

C

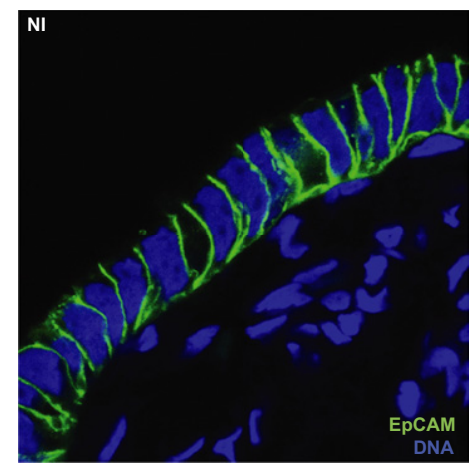

B
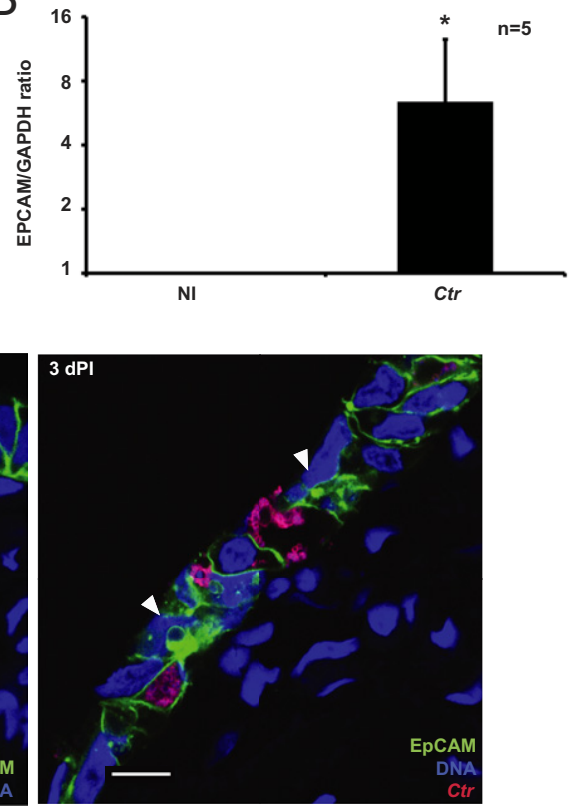
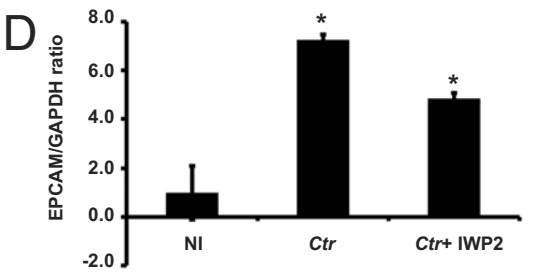

E Iv v v v

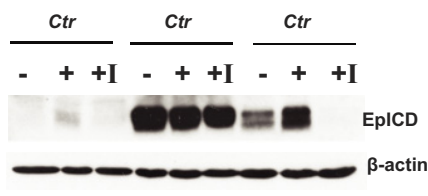

Figure 6. Ctr triggers up-regulation and activation of ovarian cancer biomarker EPCAM. A: Immunoblot shows increased levels of the epithelial cell adhesion molecule (EpCAM) full length (EpCAM FL) protein, as detected with a monoclonal antibody against the C-terminus (EpICD), in protein lysates from tissue samples of three different patients (I, II, and III). All tested lysates also showed the presence of the cleaved intracellular domain EpICD. The basal level of EpCAM protein differs, as longer exposure reveals the presence of a cleavage fragment in patient I. The C-terminal EpCAM fragment is also detected in tissues treated with $\mathrm{LiCl}(20 \mathrm{mmol} / \mathrm{L}, 24$ hours), confirming the occurrence of proteolytic EPCAM activation in the tissue and suggesting that the mechanism of processing is dependent on activation of the Wnt pathway. B: Real-time PCR of EpCAM mRNA levels normalized against glyceraldehyde-3-phosphate dehydrogenase in five patients. Error bars indicate \pm SD. C: Immunofluorescence imaging of EpCAM distribution in fallopian tubes. EpCAM (green); DNA (blue); $\operatorname{Ctr}$ (red). Scale bar $=16 \mu \mathrm{m}$. EpCAM localizes to the basolateral membrane in noninfected (NI) epithelium (left panel). Ctrinfection triggers redistribution of membrane associated EpCAM; cytoplasmic aggregates are prominent in infected, as well as neighboring cells (right panel, arrowheads). D Real-time PCR of samples showing reduction in EpCAM induction in the presence of IWP2. Error bars indicate \pm SD and are calculated for the internal variation in $\mathrm{Ctr}$ values of representative experiment. $\mathbf{E}$ : Western blot of three different patient samples (IV, V and VI) tested for EpCAM cleavage in Ctrinfection \pm and plus IWP2 (+I). All three samples show suppression of EpCAM activation in the presence of IWP2 during infection. Significance of transcriptional regulation in $\mathbf{B}$ and $\mathbf{D}$ calculated as ${ }^{*} P<0.05$; paired Student's $t$ test. EpICD, epithelial cell adhesion molecule intracellular domain. sion, we speculated that EpCAM might be de-regulated in Ctr-infected fallopian tubes. In addition, EpCAM has been previously identified as a Wnt pathway target in a hepatocellular carcinoma model. ${ }^{37}$ EPCAM was found to be positively regulated by Ctr infection on the microarray, although it failed statistical inclusion in the final hit list. To further investigate the putative role of EpCAM, we quantified EpCAM mRNA and protein levels on independent Ctr infection of fallopian tubes from 10 different women. Full length EpCAM was elevated in Ctr-infected tissue samples from three separate donors, as compared to the respective noninfected tissues (Figure 6A). This finding was reproduced in seven further samples tested (data not shown); however, some natural variation of basal EpCAM expression levels was evident. Real-time PCR confirmed that $C$ tr infection resulted in the transcriptional induction of EPCAM (Figure 6B). EpCAM immunostaining in noninfected fallopian tube epithelium was similar to the distribution of Cdh1 along lateral cell membranes (Figure 6C, left). Cytoplasmic EpCAM-positive dots were detected in subapical regions. By contrast, infected tissue exhibited a marked redistribution of EpCAM, with a loss of basolateral restriction and dispersal of the immunofluorescence signal. Patches of EpCAM-positive aggregates were detected throughout the cytoplasm (Figure $6 \mathrm{C}$, right). Notably, EpCAM staining was strongest in cells neighboring inclusion-containing cells. The change in staining pattern was indicative of EpCAM activation, consistent with the often diffuse cellular distribution of EpCAM in histological tumor samples. ${ }^{38}$

The oncogenic potential of EpCAM is not only mediated by increased expression levels, but also by proteolytic processing of the membrane bound form. ${ }^{39}$ We observed EpCAM proteolytic cleavage in infected fallopian tube lysates (Figure 6A) using an antibody against the EpCAM intracellular domain, which detects both full length EpCAM protein and a cleaved cytoplasmic fragment. Although basal levels of EpCAM expression and rates of processing differed among samples taken from different individuals, likely due to different genetic backgrounds, we observed markedly increased levels of both full length EpCAM protein and its proteolytic fragment in Ctr infection in all tested samples (Figure 6, A and E). Lithium chloride treatment of noninfected samples also induced EpCAM up-regulation and activation, in a manner similar to that observed in Ctr infection, corroborating the notion that EpCAM protein levels are responsive to Wnt activity (Figure 6A). Interestingly, IWP2 reduced transcriptional induction of EpCAM approximately twofold (Figure 6D) indicating that the transcriptional response was dependent on active Wnt signaling. To confirm the contribution of paracrine Wnt secretion to the processing of EpCAM, we analyzed the effect of the inhibitor, IWP2. Protein extracted from three different fallopian epithelial samples infected with Ctr for 48 hours in the presence and absence of IWP2 were probed with anti-EpCAM in- 
tracellular domain. In all cases, IWP2 inhibited EpCAM proteolytic processing during infection (Figure 6E). Thus, EpCAM regulation in the fallopian tube occurs downstream of Wnt activation.

Our data clearly indicate a general Wnt-dependent activation of EpCAM signaling in response to Ctr infection. Importantly, the upregulation and redistribution of EpCAM was pronounced in the noninfected surrounding epithelium representative of the paracrine influence of $\mathrm{Ctr}$ infection.

\section{Discussion}

Using an ex vivo human fallopian tube model to gain insight into the pathogenic mechanisms of Ctr, we observed a prominent disturbance of epithelial homeostasis during acute infection. Confocal immunofluoresence microscopy revealed substantial changes in epithelial cell adhesion and polarity, and increased proliferation, comparable to that observed with known inducers of Wnt secretion. Gene expression tissue profiling and protein analysis of Ctr-infected tubal fragments in the presence of a Wnt secretion inhibitor showed that Ctr induced changes were highly dependent on active Wnt signaling. We detected the oncogene markers, OLFM4 and EpCAM, as Wnt-regulated targets during Ctr infection. Interestingly, both the changes in tissue morphology and the Wnt-dependent expression of protein biomarkers extended to neighboring, uninfected cells suggesting a paracrine influence of Ctr-infected cells.

In the absence of a functional adaptive immune system in our ex vivo model, the observed epithelial rearrangements could be considered to result from an early pathogen triggered response. However, contrasting to other pathogens, Ctr is not effective in eliciting an early proinflammatory response. Typically, Ctr genital tract infections are asymptomatic with no significant cytokine release detected in vivo until 24 hours postinfection. ${ }^{40}$ Extending this notion, Lad et al ${ }^{41}$ showed that NF- $\kappa \mathrm{B}$ activation is inhibited in vitro via Ctr-mediated p65 degradation, suggesting that Ctr down-regulates the early host inflammatory response. Our finding of a strong induction of OFLM4 corroborates the negative influence of Ctr on proinflammatory pathways: OLFM4 is known to suppress NF- $\kappa$ B pathway activation and to down-regulate innate immunity in an in vivo mouse model of Helicobacter pylori infection. ${ }^{42}$ Histologically, Ctr infections of the genital tract can also be discriminated from those of other bacterial etiologies; for example, tissue samples from patients with Ctr-positive acute epididymitis are largely devoid of abscesses and exhibit minimal structural damage compared with those from Escherichia coli positive samples. ${ }^{43}$ Consistent with our own observations, the same study reported increased proliferation of epithelial cells, which appeared to be Ctr-specific. These observations indicate that Ctr-mediated pathogenesis differs from the typical progressive inflammatory manifestation of infections in that epithelial homeostasis is disturbed before inflammatory destruction.
Our functional analysis of ex vivo fallopian tube Ctr infection, in accordance with in vitro studies by Prozialeck et $\mathrm{al}^{4}{ }^{44}$ revealed that $\beta$-catenin was recruited by $C$ tr at the beginning of the cellular infection and was subsequently sequestered to the inclusion. $\beta$-catenin is a major transducer of the Wnt pathway within tissues ${ }^{25}$, and because of this we hypothesized that its recruitment to the inclusion might alter canonical Wnt signaling. Interestingly, siRNA-mediated depletion of $\beta$-catenin in cell culture impaired bacterial growth, indicating an integral role for this molecule in Ctr replication, while IWP2-mediated inhibition of paracrine Wnt secretion stimulated Ctr replication. This suggests differential effects of $\beta$-catenin recruitment and Wnt signaling on Ctr replication within the primary infected cells. Host cell activation by Wnt, which promotes $\beta$-catenin nuclear translocation, might antagonize $\beta$-catenin recruitment to the inclusion.

Using the Wnt secretion inhibitor, IWP2, we were able to assess the dependence of the tissue transcriptional response during acute Ctr infection on paracrine Wnt signaling. Of 2279 infection-specific regulated genes, we found only $\sim 400$ genes were similarly regulated, independent of Wnt activity status. The role of Wnt signaling in tissue homeostasis and disease is well-documented. ${ }^{9}$ However, our study provides the first evidence for a direct link between pathogen colonization of a mucosal surface and activation of the Wnt pathway. This observation emphasizes the importance of cell-to-cell communications in complex biological systems and their relevance as targets of infection.

Our findings also reveal remarkable parallels between Ctr-induced changes in epithelial tissue homeostasis and various pathologies of the genital tract that are characterized by changes in Wnt regulation. For example, previous work has shown that inactivation of GSK3 $\beta$ is one of the key events conferring resistance to cisplatin in an aggressive form of ovarian cancer. ${ }^{30}$ In addition, in a model of xenografted human endometrial tissue, inactivation of GSK3 $\beta$ triggered proliferation of epithelial cells. ${ }^{29}$ This observation is in striking accordance with our finding of increased cell proliferation during Ctr infection and increased levels of phospho-GSK $3 \beta$. We also determined that increased cell proliferation could be partially inhibited by blocking Wnt transmission. Increased cell proliferation and loss of cell adhesion and polarity are generally associated with an increased risk of cellular transformation within the epithelium. Despite existing epidemiological evidence linking Ctr infection and cancer, ${ }^{45,46}$ a confirmed etiological link with genital cancer has not yet been established in a defined biological system. Our finding that Ctr infection both increased EpCAM expression and enhanced its proteolytic activation provide a first molecular link between Ctr infection and the capacity for cell transformation in the fallopian tube. Even if the acute infection process studied here is unlikely to cause cancerous lesions in situ, Ctr appears to trigger molecular changes in surrounding epithelium, which could favor transformation. Increases in EpCAM expression are likely to contribute to a loss of adhesion, due to a negative effect on the strength of Cdh1 homophilic interactions. ${ }^{36}$ In addition, EpCAM proteolytic activation 
could be part of the signaling network that transduces Wnt signals to the nucleus, because it has been shown that an EpCAM cleavage fragment can form a transcriptionally active complex with $\beta$-catenin and $\mathrm{FH} 2$ in the nucleus of activated cells. ${ }^{39}$

Our identification of OLFM4 as a robust marker of Ctr-infected tissue implicates a potentially altered differentiation status of fallopian epithelial cells. OLFM4 is strongly enriched in grade I highly differentiated cancers, but absent from both normal tissue and grade III undifferentiated cancers. ${ }^{47}$ There is also a correlation between OLFM4 expression and the differentiation status of gastric and colon cancers. ${ }^{48}$ Perhaps of most relevance to this latest study is that OLFM4 expression and distribution is associated with the progression of intraepithelial neoplasia to invasive squamous cell carcinoma in the cervical epithelium. ${ }^{48}$ Both EpCAM and OLFM4 have been implicated in malignant transformation, where their high expression levels are indicative of pluripotency and a less differentiated state in colon mucosa. ${ }^{49,50}$ In addition to OLFM4 and EpCAM up-regulation, we also validated the Wnt-dependent up-regulation of other cancerassociated determinants, including LCN2, SP100, OCT4, and TCF2 (see Supplemental Figure S3 at http://ajp. amjpathol.org). One might speculate that dysregulation of the expression of these factors in the female genital mucosa could also be involved in loss of differentiation/ adhesion and increased proliferation ${ }^{51-53}$ and could jointly promote a pre-malignant environment.

In summary, our data obtained with an ex vivo tissue infection model point to a Ctr-induced shift in epithelial homeostasis toward decreased differentiation, accelerated proliferation, and a cell adhesion-defective state. Of particular interest from the perspective of pathology of potential long-term sequelae of Ctr infection, is the discovery of distal phenotypic and functional changes of noninfected cells. Thus, a better understanding of the communications between infected and noninfected cells appears to be essential to explain the mechanisms of Ctr-induced pathologies.

\section{Acknowledgments}

The authors thank Drs. Lesley Ogilvie, Kate Holden-Dye, and Thomas Kessler for critically reading and editing the manuscript.

\section{References}

1. Westrom LV: Chlamydia and its effect on reproduction. J Br Fer Soc 1996, 1:23-30

2. Crow J, Amso NN, Lewin J, Shaw RW: Morphology and ultrastructure of Fallopian-tube epithelium at different stages of the menstrual-cycle and menopause. Hum Reprod 1994, 9:2224-2233

3. Lyons RA, Saridogan E, Djahanbakhch O: The reproductive significance of human Fallopian tube cilia. Hum Reprod Update 2006, 12:363-372

4. Rajalingam K, Sharma M, Lohmann C, Oswald M, Thieck O, Froelich CJ, Rudel T: Mcl-1 is a Key Regulator Of Apoptosis Resistance in Chlamydia trachomatis-infected cells. PLoS One 2008, 3:e3102

5. Hackstadt $\mathrm{T}$ : Redirection of host vesicle trafficking pathways by intracellular parasites. Traffic 2000, 1:93-99
6. Heuer D, Rejman LA, Machuy N, Karlas A, Wehrens A, Siedler F, Brinkmann V, Meyer TF: Chlamydia causes fragmentation of the Golgi compartment to ensure reproduction. Nature 2009, 457:731-735

7. Grieshaber SS, Grieshaber NA, Miller N, Hackstadt T: Chlamydia trachomatis causes centrosomal defects resulting in chromosomal segregation abnormalities. Traffic 2006, 7:940-949

8. Rajalingam K, Sharma M, Paland N, Hurwitz R, Thieck O, Oswald M, Machuy N, Rudel T: IAP-IAP Complexes Required for Apoptosis Resistance of C. trachomatis Infected Cells. PLoS Pathog 2006, 2:e114

9. Clevers $\mathrm{H}$ : Wnt/beta-catenin signaling in development and disease Cell 2006, 127:469-480

10. Reya $\mathrm{T}$, Clevers $\mathrm{H}$ : Wnt signalling in stem cells and cancer. Nature 2005, 434:843-850

11. Kiecker C, Niehrs C: A morphogen gradient of Wnt/beta-catenin signalling regulates anteroposterior neural patterning in Xenopus. Development 2001, 128:4189-4201

12. Clements WM, Wang J, Sarnaik A, Kim OJ, MacDonald J, FenoglioPreiser C, Groden J, Lowy AM: beta-Catenin mutation is a frequent cause of Wnt pathway activation in gastric cancer. Cancer Res 2002, 62:3503-3506

13. Daniels DL, Weis WI: Beta-catenin directly displaces Groucho/TLE repressors from Tcf/Lef in Wnt-mediated transcription activation. Nat Struct Mol Biol 2005, 12:364-371

14. Yap AS, Brieher WM, Gumbiner BM: Molecular and functional analysis of cadherin-based adherens junctions. Annu Rev Cell Dev Biol 1997, 13:119-146

15. Cooper MD, Rapp J, Jeffery-Wiseman C, Barnes RC, Stephens DS: Chlamydia trachomatis infection of human fallopian tube organ cultures. J Gen Microbiol 1990, 136:1109-1115

16. Hvid M, Baczynska A, Deleuran B, Fedder J, Knudsen HJ, Christiansen $\mathrm{G}$, Birkelund $\mathrm{S}$ : Interleukin-1 is the initiator of Fallopian tube destruction during Chlamydia trachomatis infection. Cell Microbiol 2007, 9:2795-2803

17. Reddy BS, Rastogi S, Das B, Salhan S, Verma S, Mittal A: Cytokine expression pattern in the genital tract of Chlamydia trachomatis positive infertile women - implication for T-cell responses. Clin Exp Immunol 2004, 137:552-558

18. Robertson D, Savage K, Reis-Filho JS, Isacke CM: Multiple immunofluorescence labelling of formalin-fixed paraffin-embedded (FFPE) tissue. BMC Cell Biol 2008, 9:13

19. Churchill GA: Fundamentals of experimental design for cDNA microarrays, Nat Genet 2002, 32:Suppl. 490-5

20. Schmittgen TD, Zakrajsek BA: Effect of experimental treatment on housekeeping gene expression: validation by real-time, quantitative RT-PCR. J Biochem Biophys Methods 2000, 46:69-81

21. Thiery JP, Acloque H, Huang RY, Nieto MA: Epithelial-mesenchymal transitions in development and disease. Cell 2009, 139:871-890

22. Klebes $\mathrm{A}$, Knust $\mathrm{E}$ : A conserved motif in Crumbs is required for E-cadherin localisation and zonula adherens formation in Drosophila. Curr Biol 2000, 10:76-85

23. Chitaev NA, Troyanovsky SM: Adhesive but not lateral E-cadherin complexes require calcium and catenins for their formation. J Cell Biol 1998, 142:837-846

24. Furuse $M$, Itoh M, Hirase $T$, Nagafuchi A, Yonemura S, Tsukita S: Direct association of occludin with ZO-1 and its possible involvement in the localization of occludin at tight junctions. J Cell Biol 1994, 127:1617-1626

25. Nelson WJ, Nusse R: Convergence of Wnt, beta-catenin, and cadherin pathways. Science 2004, 303:1483-1487

26. Rubinfeld B, Albert I, Porfiri E, Fiol C, Munemitsu S, Polakis P: Binding of GSK3beta to the APC-beta-catenin complex and regulation of complex assembly. Science 1996, 272:1023-1026

27. Clement-Lacroix P, Ai M, Morvan F, Roman-Roman S, Vayssiere B, Belleville C, Estrera K, Warman ML, Baron R, Rawadi G: Lrp5-independent activation of Wnt signaling by lithium chloride increases bone formation and bone mass in mice. Proc Natl Acad Sci USA 2005, 102:17406-17411

28. Prigent $\mathrm{C}$, Dimitrov S: Phosphorylation of serine 10 in histone $\mathrm{H} 3$, what for? J Cell Sci 2003, 116:3677-3685

29. Polotsky AJ, Zhu L, Santoro N, Pollard JW: Lithium chloride treatment induces epithelial cell proliferation in xenografted human endometrium. Hum Reprod 2009, 24:1960-1967 
30. Cai G, Wang J, Xin X, Ke Z, Luo J: Phosphorylation of glycogen synthase kinase- 3 beta at serine 9 confers cisplatin resistance in ovarian cancer cells. Int J Oncol 2007, 31:657-662

31. Henderson BR: Nuclear-cytoplasmic shuttling of APC regulates betacatenin subcellular localization and turnover. Nat Cell Biol 2000 2:653-660

32. Chen B, Dodge ME, Tang W, Lu J, Ma Z, Fan CW, Wei S, Hao W, Kilgore J, Williams NS, Roth MG, Amatruda JF, Chen C, Lum L: Small molecule-mediated disruption of Wnt-dependent signaling in tissue regeneration and cancer. Nat Chem Biol 2009, 5:100-107

33. Grover P, Hardingham J, Cummins A: Stem cell marker olfactomedin 4: critical appraisal of its characteristics and role in tumorigenesis. Cancer Metastasis Rev 2010, 29:761-775

34. Sato T, Vries RG, Snippert HJ, van DE Wetering M, Barker N, Stange DE, van Es JH, Abo A, Kujala P, Peters PJ, Clevers H: Single Lgr5 stem cells build crypt-villus structures in vitro without a mesenchymal niche. Nature 2009, 459:262-265

35. Kobel M, Kalloger SE, Boyd N, McKinney S, Mehl E, Palmer C, Leung S, Bowen NJ, Ionescu DN, Rajput A, Prentice LM, Miller D, Santos J, Swenerton K, Gilks CB, Huntsman D: Ovarian carcinoma subtypes are different diseases: implications for biomarker studies. PLoS Med 2008, 5:e232

36. Winter MJ, Nagelkerken B, Mertens AE, Rees-Bakker HA, Briaire-de Bruijn IH, Litvinov SV: Expression of Ep-CAM shifts the state of cadherin-mediated adhesions from strong to weak. Exp Cell Res 2003, 285:50-58

37. Yamashita T, Budhu A, Forgues M, Wang XW: Activation of hepatic stem cell marker EpCAM by Wnt-beta-catenin signaling in hepatocellular carcinoma. Cancer Res 2007, 67:10831-10839

38. Yanamoto S, Kawasaki G, Yoshitomi I, Iwamoto T, Hirata K, Mizuno A: Clinicopathologic significance of EpCAM expression in squamous cell carcinoma of the tongue and its possibility as a potential target for tongue cancer gene therapy. Oral Oncol 2007, 43:869-877

39. Maetzel D, Denzel S, Mack B, Canis M, Went P, Benk M, Kieu C, Papior P, Baeuerle PA, Munz M, Gires O: Nuclear signalling by tumour-associated antigen EpCAM. Nat Cell Biol 2009, 11:162-171

40. Ingalls RR, Rice PA, Qureshi N, Takayama K, Lin JS, Golenbock DT: The inflammatory cytokine response to Chlamydia trachomatis infection is endotoxin mediated. Infect Immun 1995, 63:3125-3130

41. Lad SP, Li J, da Silva CJ, Pan Q, Gadwal S, Ulevitch RJ, Li E: Cleavage of p65/RelA of the NF-kappaB pathway by Chlamydia, Proc Natl Acad Sci USA 2007, 104:2933-2938

42. Liu W, Yan M, Liu Y, Wang R, Li C, Deng C, Singh A, Coleman WG, Rodgers GP: Olfactomedin 4 down-regulates innate immunity against
Helicobacter pylori infection. Proc Natl Acad Sci USA 2010, 107:11056-11061

43. Hori S, Tsutsumi Y: Histological differentiation between chlamydial and bacterial epididymitis: nondestructive and proliferative versus destructive and abscess forming-immunohistochemical and clinicopathological findings. HumPathol 1995, 26:402-407

44. Prozialeck WC, Fay MJ, Lamar PC, Pearson CA, Sigar I, Ramsey KH: Chlamydia trachomatis disrupts $\mathrm{N}$-cadherin-dependent cell-cell junctions and sequesters beta-catenin in human cervical epithelial cells. Infect Immun 2002, 70:2605-2613

45. Smith JS, Bosetti C, Muñoz N, Herrero R, Bosch FX, Eluf-Neto J, Meijer CJLM, van den Brule AJC, Franceschi S, Peeling RW: Chlamydia trachomatis and invasive cervical cancer: a pooled analysis of the IARC multicentric case-control study. Int J Cancer 2004, 111:431439

46. Ness RB, Goodman MT, Shen C, Brunham RC: Serologic evidence of past infection with Chlamydia trachomatis, in relation to ovarian cancer. J Infect Dis 2003, 187:1147-1152

47. Liu W, Zhu J, Cao L, Rodgers GP: Expression of hGC-1 is correlated with differentiation of gastric carcinoma. Histopathology 2007, 51 : 157-165

48. Yu L, He M, Yang Z, Chen G, Li M, Wang L, Chen S: Olfactomedin 4 is a marker for progression of cervical neoplasia. Int J Gynecol Cancer 2011, 21:367-372

49. van der Flier LG, Haegebarth A, Stange DE, van DE WM, Clevers $H$ : OLFM4 is a robust marker for stem cells in human intestine and marks a subset of colorectal cancer cells. Gastroenterology 2009, 137 $15-17$

50. Dalerba P, Dylla SJ, Park IK, Liu R, Wang X, Cho RW, Hoey T, Gurney A, Huang EH, Simeone DM, Shelton AA, Parmiani G, Castelli C, Clarke MF: Phenotypic characterization of human colorectal cancer stem cells. Proc Natl Acad Sci USA 2007, 104:10158-10163

51. Cho H, Kim JH: Lipocalin2 expressions correlate significantly with tumor differentiation in epithelial ovarian cancer. J Histochem Cytochem 2009, 57:513-521

52. Peng S, Maihle NJ, Huang Y: Pluripotency factors Lin28 and Oct4 identify a sub-population of stem cell-like cells in ovarian cancer. Oncogene 2010, 29:2153-2159

53. Maestro MA, Cardalda C, Boj SF, Luco RF, Servitja JM, Ferrer J: Distinct roles of HNF1beta. HNF1alpha, and HNF4alpha in regulating pancreas development, beta-cell function and growth, Endocr Dev 2007, 12:33-45 